\title{
Синицкий Д.А.
}

\section{Моральные дилеммы, эмотивизм и рационализация эмоций}

Обнинский институт атомной энергетики - филиал ФГБОУ ВО «Национальный исследовательский ядерный университет «МИФИ»

(Россия, Обнинск)

doi: $10.18411 / \mathrm{j}-06-2020-247$

idsp: ljournal-06-2020-247

\section{Аннотация}

Статья посвящена анализу проблематики моральных дилемм в контексте эмотивизма. Возможно ли преодолеть крайности эмотивизма и антиэмотивизма при решении моральных дилемм на основе современных теоретических моделей эмоций? В статье обосновывается возможность адекватного синтетического подхода к теоретической рационализации эмоциональной и моральной сфер на основе теории эмоций А. Ортони, Дж. Л. Клора и А. Коллинза (модель эмоций ОСС) и парадигмы BDI («Убеждение, Желание, Намерение»).

Ключевые слова: моральная дилемма, эмотивизм, модель эмоций ОСС, парадигма BDI.

\section{Abstract}

The article is devoted to the analysis of the problems of moral dilemmas in the context of emotivism. Is it possible to overcome the extremes of emotivism and anti-emotivism in solving moral dilemmas based on modern theoretical models of emotions? The article substantiates the possibility of an adequate synthetic approach to the theoretical rationalization of the emotional and moral spheres based on the theory of emotions by A. Ortoni, J. L. Clore and A. Collins (model of emotions of OCC) and the BDI paradigm ("Belief, Desire, Intention").

Keywords: moral dilemma, emotivism, OCC model of emotions, BDI paradigm.

\section{Дилеммы и проблемы (вместо введения).}

В философской, этической, правовой, психологической, логической, нейробиологической литературе не прекращаются дискуссии относительно природы моральных дилемм, путей их разрешения, или, хотя бы, объяснения и понимания.

Под моральной дилеммой понимается ситуация принятия решения в условиях выбора, когда любые альтернативы выбора не являются морально безупречными. Соответственно отсутствие моральной безупречности означает несоответствие какомулибо моральному положению, имеющему характер необходимого морального предписания. Как должен вести себя человек, оказавшись в подобной ситуации? Должен ли он принять какое-либо решение и осуществить соответствующие принятому решению действия из подразумеваемых альтернатив в условиях ограниченного выбора, несмотря на их моральную сомнительность, а, зачастую, и моральную преступность, или он должен отказаться от действий вообще, а может быть и от поиска решения? Чем может быть оправдан подобный выбор, и может ли он быть оправдан в принципе? Возможно ли вообще какое-либо разумное и при этом согласующееся с принимаемыми моральными нормами объяснение (рационализация) сделанного выбора, или действия человека в подобных ситуациях могут носить случайный характер (например, под воздействием аффекта, произведенного самой ситуацией выбора), не поддаваться разумному объяснению и пр. Каковы должны быть требования к совокупностям моральных предписаний (моральным кодексам), чтобы не допускать или, наоборот, учитывать подобные ситуации? Не оказывается ли наличие моральных дилемм поводом для сомнения в отношении возможности рационального обоснования 
моральных кодексов? Как оказываются связаны между собой универсальные моральные принципы и нормы (если они вообще возможны и имеют практический смысл) и конкретные поступки и дела конкретных людей, от каких факторов зависит степень универсальности моральных требований? Является ли человек абсолютно рациональным в своих действиях и моральности? Возможно ли рациональным (то есть разумным) образом организовать или, хотя бы, описать, объяснить моральность человека, ведь человек сам себя именует Homo sapiens, Человек Разумный, а в новейшей биологической классификации видов даже Homo sapiens sapiens, то есть, как минимум неоднократно разумный, что несомненно должно звучать гордо?

Люди стали спорить на подобные темы еще в древности, вспомним хотя бы позицию Сократа (в изложении Платона), которую сейчас принято называть громким словосочетанием «этический рационализм». Если в двух словах, то Сократ считал, что человек может выработать моральное знание о том, что есть зло, и что есть добро (или как тогда говорили, «благо»), так сказать, само по себе, безотносительно частных примеров, и этому знанию научить других.

Споры в отношении моральных дилемм не прекращаются и поныне, что, несомненно свидетельствует о большой заинтересованности людей в нахождении решений подобных проблем, удовлетворительных в каких-то логическом, этическом и практически-утилитарных смыслах если не для всех, то, по крайней мере, для многих. В конечном счете, наличие моральных дилемм в качестве предмета споров ставит более глобальные вопросы, касающиеся организации человеческого социума и человеческой культуры в морально-этическом, поведенческом, правовом, рациональном/иррациональном и других аспектах.

Чтобы не быть голословными и далее, приведем в качестве примеров несколько ситуаций выбора, которые достаточно надуманны, но тем не менее часто обсуждаются в литературе и являются этаким морализаторским аналогом мысленных экспериментов, которые так любят ставить физики. Кстати, приходилось слышать упреки в черствости в адрес философов, беспристрастно рассуждающих о моральных дилеммах, но если вспомнить мысленные эксперименты физиков с мило беседующими с помощью квантовой телепортации Бобом и Алисой на фоне падающих лифтов с людьми, котов, не живых и не мертвых от страха быть отравленными цианидом и настоящих демонов, открывающих и закрывающих различные дверцы, то приводимые ниже примеры не покажутся чем-то из ряда вон выходящим.

Пример 1. По рельсам мчится вагонетка (как вариант - трамвай, потерявший управление), на пути которой стоит группа людей из, скажем, 10 человек, а между мчащейся вагонеткой и людьми находитесь Вы в качестве стрелочника (а точнее субъекта, принимающего или не принимающего решения и выполняющего или не выполняющего действия; таких субъектов, вымышленных или реально существующих мы далее будем называть агентами) и стрелочный механизм, позволяющий направить движение вагонетки на другой путь, на котором, однако, стоит (варианты - сидит на рельсах, глубоко задумавшись о проблематике моральной ответственности или лежит в стельку пьяный) еще один человек. Какое решение вы примете и что вы сделаете пожертвуете одним ради десяти, переведя стрелку, или не предпримите никаких действий?

Пример 2. Он не сильно отличается от первого, за исключением того, что никакой стрелки и ответвления пути нет, а Вы находитесь на мосту через рельсы и рядом с Вами какой-то толстяк (вариант - толстый, пьяный в доску и нелицеприятный философ, что-то бормочущий о свободе воли). При этом Вы знаете, что если Вы сбросите с моста этого толстяка под колеса вагонетки, то она остановится. Каким будет Ваш выбор?

Это и есть примеры моральных дилемм - какой выбор Вы бы не сделали и в первом примере и во втором, он будет морально ущербным, если Вы, конечно, помните 
о том, что говорил когда-то И. Кант, а именно - что нельзя использовать людей в качестве средства даже для достижения благих целей (ведь спасение хоть одного, хоть десяти вышеупомянутых есть несомненное благо), и свято верите в правоту кантовских слов.

Это только два примера (наиболее популярных и часто обсуждаемых), но на самом деле ситуаций, связанных с необходимостью принятия решений, после которых должны будут осуществляться действия, морально порицаемые, неприемлемые или несоответствующие какому-либо моральному предписанию, можно придумать достаточно много. Более того, надуманность этих примеров только кажущаяся.

Приведем еще два примера, автором которых являются лауреат Нобелевской премии по экономике 2002 года Д. Канеман и его коллега А. Тверски. (См. напр. [3]).

Пример 3. Представьте, что Соединенные Штаты готовятся к вспышке необычной азиатской болезни, которая, как ожидается, убьет 600 человек. Были предложены две альтернативные программы борьбы с этой болезнью. Предположим, что точные научные оценки последствий данных программ следующие. Если будет проводиться программа А, то удастся спасти 200 человек. Если же будет проводиться программа В, то с вероятностью 33,3\% будут спасены все и с вероятностью $66,6 \%$ не выживет никто. Какую из программ вы одобрите?

Пример 4. После аналогичного вступления, говорится, что если будет принята программа C, то 400 человек умрет. Если же будет принята программа D, то с вероятностью $1 / 3$ не погибнет никто, а с вероятностью 2/3 умрут 600 человек. Какую из программ вы одобрите?

Люди в реалиях своей социальной жизни постоянно сталкиваются с подобного сорта проблемами, и ситуации, где человеческая жизнь является своеобразной и бесконечно высокой платой за сделанный моральный выбор, к сожалению, не так уж и редки.

Анализ этих и подобных примеров (а формулировки некоторых моральных дилемм восходят еще к временам античности и средневековья) разделили интересующихся на уровне теоретических рассуждений подобной проблематикой философов, этиков, логиков, нейробиологов и нейропсихологов (а также просто биологов, психологов, и прочих любопытствующих) на различные группы, которым философы тут же придумали названия в зависимости от оснований этого разделения.

Так, образовалась группа морально-этических теоретиков, которые полагают, что моральных дилемм, как проблемных ситуаций, приводящих к несовместимости какого-то частного случая с универсальным моральным законом (императивом, предписанием) не существует. В соответствии с их точкой зрения, изначальные требования к положениям, принимаемым в качестве моральных законов, требуют универсальности и совершенства законов, их совокупность, образующая моральный кодекс, внутренне согласована на основе логических критериев, а моральные дилеммы в этом плане и не дилеммы вовсе, а описания частных случаев, подлежащие уточнению, дополнению и согласованию с моральным кодексом. То есть, моральная дилемма не является чисто этической проблемой, а скорее проблемой нехватки информации о частном случае, который можно и нужно за счет пополнения информации, в конце концов, подвести под тот или иной моральный закон, и, тем самым, обосновать и оправдать.

Другая группа состоит из теоретиков, предполагающих, что моральные дилеммы являются частью этико-моральной проблематики, связанной с возможностью (или невозможностью) сформулировать наиболее совершенный моральный кодекс, содержащий логически совместимые моральные нормы. А.В.Разин первых обозначает как рационалистов, а вторых как империстов, относя к первым, например, Ф.Аквинского и Д.Дэвидсона, а ко вторым - Ж.-П. Сартра, Р. Маркеса, М. Д. Хаузера, А. Макинтайра и др. [7]. 
Нас, однако, далее будет интересовать группа теоретиков, которую называют эмотивистами. Название это связано со словом «эмоция». Обычно в исторических этико-философских экскурсах эмотивизмом называют подход к рассмотрению этики, как области, не являющейся строго говоря, областью научного знания, в силу того, что этические и моральные суждения и высказывания большей частью выражают эмоции и оценки того или иного субъекта и поэтому не проверяемы на истинность или ложность, или как говорят, «не верифицируемы», а потому не могут быть содержанием научного знания и даже являются бессмысленными.

Более того, нередко в основаниях эмотивизма лежит противопоставление сферы эмоциональной, то есть того, что в человеке связано с аффектами, сиюминутными желаниями, эмоциями, настроением, чувствами - сфере рациональной, то есть тому, что мы обычно связываем с пониманием, выражением человеческих мыслей в языке с помощью терминов и высказываний, рассуждением, доказательством, обоснованием, аргументацией и пр. И зачастую это противопоставление формулируется как дихотомия иррациональное/рациональное, то есть мир чувств и эмоций объявляется частью иррационального и противопоставляется разуму человека.

\section{Дихотомия рациональное/иррациональное в контексте дихотомии}

\section{моральное/эмоциональное}

Здесь необходимо прямо заявить, что эмотивизм эмотивизму рознь. Одно дело - не считать этику наукой в силу непроверяемости утверждений той или иной этической доктрины. Такая позиция была характерна отчасти для логического позитивизма, особенно в наиболее радикальных его формах (напомним, что логический позитивизм - это направление в философии прошлого века, ратовавшее за использование средств логики при анализе знания и предлагавшее целый ряд критериев научности знания, среди которых был и упомянутый принцип верифицируемости предложений, сформулированных в языке теории), отчасти - для представителей аналитической философии, отчасти для представителей естественных наук.

Другое дело - искать истоки правил, детерминирующих поведение человека в психоэмоциональной сфере. Такая позиция была характерна для Д. Юма, британского (точнее шотландского) мыслителя восемнадцатого столетия. Юм строит свою этическую теорию отталкиваясь от разработанной им же теории аффектов, объясняющих психоэмоциональную составляющую человека и его поведения. Поведение человека регулируется моральными правилами, которые детерминируются, то есть определяются самой природой, в том числе и природой человека. Человек не изобретает и не должен специально изобретать моральные правила, он просто должен следовать этим правилам, уже навязанным ему природой и образующим некие моральные чувства, например, «чувство справедливости», и в этом во многом и заключается моральная ответственность по Юму. Юм жил в эпоху Просвещения, подготовленную предшествующим столетием начала классического естествознания, и попытки перенести представления о природе, натуре и исследующем ее ученым, естествоиспытателем в буквальном смысле - выпытывающем у природы ее природные законы, на сферу общественную, на историю и другие науки об обществе и человеке вполне понятны. Не случайно многие тогда говорили и писали о «естественном праве», «естественной морали» и «естественной религии». Что может связывать человека разумного с природой - конечно его страсти, аффекты и желания. Отсюда, по Юму, и надо принимать как данность эмотивную природу морали.

Конечно, Юма (как, впрочем, и многих других философов,) можно упрекнуть в том, что его рассуждения носят умозрительный характер, но стоит ли делать такие упреки в отношении человека, жившего во времена, когда науки, изучающие сферу эмоций и аффектов, еще не сформировались (имеются в виду такие области современного научного знания, как экспериментальная психология и психофизиология, нейробиология и другие нейронауки). 
Для нас сейчас важно отметить, что различия в видах и типах эмотивизма можно искать, рассматривая соотношение двух видов теорий. Один вид теорий образуют теории эмоций (то есть их предметная область - это эмоции, аффекты, чувства, настроения и т.п.), другой - этические теории, формулирующие и обосновывающие моральные кодексы (то есть их предметная область - сами моральные кодексы и способы их формирования и обоснования). И понимание соотношения между этими двумя видами теорий может быть разным. При этом мы будем исходить из трактовки теории, как совокупности высказываний, сформулированных в языке теории и обладающих целым комплексом разнообразных характеристик, на детализации которых мы не будем останавливаться. Так или иначе, все эти характеристики трактуются нами как результат рациональной активности человека, а теория, таким образом - как некоторое воплощение рационализма.

Вариант 1. Рационалистический этико-эмотивный автономизм. Теоретик допускает независимое существование двух видов теорий. Эмоции - к эмоциям, моральные кодексы - к моральным кодексам, мухи - к мухам, котлеты - к котлетам. Теоретик допускает существование обоих видов теорий, но только как не связанных друг с другом. То есть рационализация (в форме построения теории) возможна и в отношении «мира эмоций» и в отношении «мира моральных законов», но они никак не зависят друг от друга.

Вариант 2. Рационалистический эмотивный редукционизм. (Эмотивизм Юма.) Теоретик считает, что не надо строить никакой особой этической теории. Для рационализации как психоэмоциональной сферы, так и сферы морали достаточно построить адекватную по его меркам теорию эмоций, чувств и настроений.

Вариант 3. Рационалистический эмотивный морализм. Теоретик полагает, что рационализация обеих сфер в форме теорий возможна, при этом теории морали могут (как вариант - обязаны) выступать некими метатеориями по отношению к теориям эмоций, но не наоборот, и позволяют интерпретировать и оценивать мир чувств, судить о психоэмоциональной сфере с позиций нравственности.

Вариант 4. Рационалистический моральный (этический) эмотивизм. Теоретик полагает, что рационализация обеих сфер в форме теорий возможна, при этом теории эмоций могут (как вариант - обязаны) выступать метатеорией по отношению к теориям морали, или дополняться теориями морали.

Вариант 5. Рационалистическая морально-эмотивная дополнительность. Сочетание 3 и 4 вариантов.

Вариант 6. Рационалистический антиэмотивный морализм. Теоретик полагает, что рационализация психоэмоциональной сферы в форме теории невозможна (невозможна в принципе, так как эмоции - это сфера иррационального и их можно только испытывать, переживать, ощущать, чувствовать, но нельзя адекватно, строго и точно выразить словами, и уж тем более доказательно о них рассуждать), в то время как теории этические строить можно (и нужно), поскольку мораль поддается рационализации в форме теорий.

Вариант 7. Рационалистический антиморализм и антиэмотивизм. Теоретик полагает, что он знает, что такое рационализация и поэтому у него есть основания считать невозможным рационализацию в форме приемлемой в каком-то смысле теории ни в области эмоций, ни в области моральных кодексов. (позиция Л. Вигенштейна, «раннего» логического позитивизма).

Вариант 8. Эмотивный иррационализм или эмотивизм иррационалистического толка. Наука невозможна. Знание в форме научных теорий невозможно. Жизнь - это сплошное переживание и нервотрепка. Назад к природе! Назад к инстинктам! По ту сторону добра и зла! И т.д. и т.п. (философия жизни, экзистенциализм, отчасти феноменология и постмодерн). 
Вариант 9. Иррациональный эмотивный морализм. Наука невозможна. Знание в форме научных теорий невозможно. Только моральный закон во мне (надо мной, вокруг меня, на небесах, в телевизоре и интернете), который я должен ощущать сердцем (умиротворенно верить в него, полагаться на него, трепетно постигать через откровение свыше, радостно осознавать, благолепно подчиняться), способен дать мне возможность прожить достойно (праведно, правильно, спасти душу, даровать бессмертие души).

При этом, хотя и связанными с перечисленными выше вариантами, но вместе с тем отдельными вопросами, являются вопросы об эмотивной выразительности и моральной значимости той или иной теории.

Вопрос эмотивной выразительности связан не только с проблемой точного выражения и описания в языке того, что мы относим к переживаниям, а также провоцирования сопереживания на основе сказанного и прочитанного, но и наоборот, к тому, в какой степени фактографическая описательность языка, то есть то что называют дескриптивным характером предложений языка теории, дополняется оценочными и модальными высказываниями различного вида, в том числе как эмотивами (то есть выражениями языка, связанными с эмоциями), так и высказываниями морально-этического порядка, например с деонтическими модальностями и оценками.

Кстати, степень дескриптивности/оценочности языка теорий иногда берется в качестве одного из оснований для деления науки на различные области знания (см. напр. [2], а у неопозитивистов (иное название логических позитивистов) она была связана с осмысленностью и верифицируемостью, как критериями научности вообще.

Вопрос же этической значимости теории в значительной степени рассматривается, говоря словами В.А.Канке, как вопрос об этическом содержании различных наук, или как вопрос о том, в какой степени этическое начало присуще наукам? [4]

Очень часто в разговорах об эмотивизме указанные варианты возможного соотношения моральной теории и теории эмоций, а также упомянутые только что вопросы об эмоциональной выразительности и этической значимости оказываются смешанными и запутанными.

\section{Примеры современного эмотивизма.}

Однако пойдем далее и попытаемся рассмотреть некоторые варианты современного эмотивизма и его возможностей относительно анализа моральных дилемм.

Здесь следует отметить, конечно, значительное развитие психологии в изучении человеческих эмоций и построении соответствующих теорий эмоций. Несмотря на то, что тема страстей и аффектов была притчей во языцех со времен античности, и активно муссировалась в философии, эстетике, искусстве и религиозном богословии, естественнонаучный подход к изучению эмоций многие начинают отсчитывать с XIX века, а именно с работы Ч. Дарвина «Выражение эмоций у человека и животных» [9]. Так это или не так - историкам науки виднее, но является историческим фактом то, что со времени выхода работы Ч. Дарвина в свет, в психологии XIX, XX и первой четверти XXI века сформировалось достаточно научных школ, направлений, в которых проявило себя много выдающихся исследователей, сформулировавших огромное количество теорий эмоций. Для целей данной статьи нет смысла анализировать в каком-либо ключе все это бесконечное многообразие, а если говорить о научных тенденциях последних десятилетий, то на наш взгляд ознакомительное представление о состоянии современных исследований может дать обзорный сборник [10].

Резюмируем - научная рационализация мира эмоций идет полным ходом. И в рамках этой рационализации мы можем встретить различные теоретические позиции, относящиееся к перечисленным выше вариантам. Так, примером второго и четвертого 
вариантов относительно соотношения эмоций и моральности, могут служить теоретические позиции американского нейропсихолога Майкла Газзаниги (см. напр. [1]), и португальского нейропсихолога Антонио Дамасио (см.напр. [8] с его гипотезой соматического маркера.

«Соматические маркеры» - это ощущения в теле, которые связаны с эмоциями, например, ощущение человеком учащенного сердцебиения в связи тревогой и страхом, или ощущение человеком тошноты и желудочных спазмов в связи с неприязнью и отвращением по отношению к чему-либо (кому-либо). Дамасио в своих исследованиях, опираясь на большой эмпирический материал, попытался обосновать тезис о том, что подобные психосоматические реакции сильно влияют на последующее принятие человеком решения, делая таким образом сам процесс принятия решения не просто эмоционально окрашенным, но психофизиологически зависящим от эмоциональной сферы. Эксперименты и исследования, проводимые Дамасио и его коллегами, интерпретировались Дамасио в пользу локализации областей мозга человека, ответственных за обработку соматических маркеров, в первую очередь в вентромедиальной префронтальной коре и миндалине. Различные мозговые нарушения механизмов эмоциональных реакций резко снижали способность людей вообще принимать решения в условиях выбора [8].

Более радикальную позицию рационалистического эмотивного редукционизма (вариант 2) на основе нейробиологической теории развивает Майкл Газзанига.

Согласно его позиции, нейробиология дает богатый эмпирический материал для того, чтобы заявить, что человеческое сознание и осознание самого себя как некой личности - Я, если использовать фихтеанскую терминологию — основано на функционировании и протекании в мозге человека рассредоточенных и конкурирующих друг с другом систем и процессов, зависящих от модульной организации нейронной сети, что говорит, по мнению М. Газзаниги, в пользу эмерджентного характера сознания. Эмерджентность, или холизм, трактуется как появление у системы свойств, не присущих её элементам в отдельности. Кроме того, многие процессы, куда относится и нейросоматика эмоций, влияющая на принятие решений, протекает на бессознательном (или подсознательном) уровне, не осознается когнитивно, а если и осознается, то во многом post factum, задним числом.

Для того, чтобы оправдать факт осознаваемости и самоидентификации (картезианский аргумент) столь самоочевидный каждому здравомыслящему человеку, Газзанига вводит в свою теорию концепт Интерпретатора (с большой буквы), однако специфика этого Интерпретатора по Газзаниге заключается в том, что это всего лишь роль или функция, которую могут выполнять различные системы и процессы.

Так, согласно Газзаниге, человек формулирует моральные суждения уже после осуществления выбора и действий, следующих за выбором на уровне неосознаваемого первоначально механизма нейроэмоциональных реакций, как бы оправдывая их на уровне рациональности [1].

В этом контексте любопытны результаты исследования, проведенного не так давно в Национальном исследовательском университете ВШЭ А.С. Пляскиной, которые на первый взгляд, говорят в пользу версий эмотивизма в варианте Дамасио и даже в варианте Газаниги. В одной из версий опроса, опрашиваемым в качестве задания давались слегка модифицированные формулировки приведенных выше примеров 3 и 4 дилеммы Д. Канемана и А. Тверски «Азиатская болезнь». Модификация формулировок дилемм заключалась в том, что респонденту предлагалось представить себя президентом некоторой страны, в которой произошла эпидемия, и утвердить соответствующую медицинскую программу. Как отмечает А.С. Пляскина, около 35\% ответов аргументировались на основе позиций «рациональности», апеллируя так или иначе к логике расчета вероятностей. Однако большая часть ответов — около $65 \%$ 
обосновывала свой выбор на основе мировоззренчески-ценностной или эмоциональноценностной интерпретации ситуации выбора и своего собственного решения.

Однако, сразу следует отметить, во-первых, что модификация формулировок дилеммы «Азиатская болезнь» указанным А.С. Пляскиной образом усиливает личностную вовлеченность респондента в ситуацию выбора, усиливая у респондентов «внутриличностный конфликт» и «саморефлексию», что, собственно, и отмечалось автором исследования. Один из выводов, предлагаемых автором исследования «невозможность построения теории выбора в ситуациях неопределенности на сугубо рациональных основаниях и необходимость привлечения положений экзистенциальной философии и психологии». (См. [5], а также [6]). Кстати, аналогичное усиление личностной вовлеченности на основе эмоций симпатии/антипатии дают варианты первого и второго примеров дилемм, в зависимости от отношения респондентов к толстякам, философам и пьяницам.

Во-вторых, следует отметить, что первоначальное обсуждение моральной дилеммы «Азиатская болезнь» делалось Д. Канеманом и А. Тверски не в этическом контексте обсуждения моральности/аморальности принимаемого решения в условиях предлагаемого выбора, но в контексте рациональности/иррациональности такого решения, причем рациональность связывалась Д. Канеманом и А. Тверски с классической теорией полезности и способностью к аргументации на основании теоретико-вероятностного расчета, в то время как с иррациональностью ассоциировалась как морально-ценностная аргументация, так и аппеляция к эмоциям.

Тем не менее, выводы, которые делают эти исследователи, говорят о необходимости пересмотра роли классической дихотомии рациональное/иррациональное при оценке процесса принятия решения в условиях выбора, a, соответственно, и пересмотре крайних взглядов на дихотомию рациональное/иррациональное в контексте дихотомии эмоциональное/моральное(этическое) и выработки синтетических и взаимодополняющих подходов к построению теорий, что, в свою очередь, требует теоретического уточнения базовых концептов таких теорий. И если речь идет об эмотивизме, то, разумеется, таким базовым концептом является понятие эмоции.

\section{Модель эмоций ОСС.}

В качестве образца такой современной теории эмоций, в которой понятие эмоции уточняется более или менее конструктивным образом, можно привести в пример концепцию, развитую американскими психологами А. Ортони, Дж. Л. Клором и А. Коллинзом [12]. На наш взгляд она обладает целым рядом преимуществ, которые сделали ее в значительной степени популярной в наше время. Эта теория предлагает определенную, сформулированную достаточно четким и конструктивным языком теоретическую модель эмоций, которую ниже мы, отдавая дань сложившейся традиции, будем обозначать ОСС по первым буквам фамилий авторов.

Согласно ОСС, эмоции выделяются из всего множества психоэмоциональных процессов и явлений, включающих аффекты (или импульсы), собственно эмоции, настроения, темперамент и характер человека, по временной продолжительности, обычно соответствующей интервалу от нескольких секунд до нескольких часов. В модели ОСС эмоция всегда относится к чему-то (кому-то), вызывается чем-то (кем-то), направлена на что-то (на кого-то). В модели ОСС предполагается, что эмоции могут соотносится не только с актуально существующими стимулами и быть направлены на актуально существующие объекты, ситуации и события, но и на воображаемые, предполагаемые, ожидаемые и т.п. Это называется «идеаторностью» эмоций.

В соответствии с ОСС, эмоция - это процесс, протекающий по схеме «Оценка - Переживание - Регуляция». В рамках ОСС предполагается, что можно выделить конечный набор типов эмоций, и собственно, детальное уточнение характеристик, относящихся к выделяемым типам эмоций и образует ядро модели эмоций ОСС. Этот 
конечный набор состоит из 22 типов эмоций с детальными описаниями каждого типа эмоций: радость (joy), горе (distress), радость за другого (happy-for), жалость (pity), обида (resentment), злорадство (gloating), надежда (hope), страх (fear), удовлетворение (satisfaction), подтвердившийся страх (fears-confirmed), облегчение (relief), разочарование (disappointment), гордость (pride), стыд (shame), восхищение (admiration), укоризна (reproach), благодарность (gratitude), гнев (anger), удовольствие (gratification), раскаяние (remorse), симпатия (liking), антипатия (disliking) [12].

Люди в рамках модели эмоций ОСС трактуются не просто как агенты, наделенные рациональностью, но как агенты, которые, с одной стороны, мир воспринимают на перцептивном уровне, при этом наделены эмоциями и переживают их, а на когнитивном уровне осознают свои ощущения, чувства и эмоции, могут о них рассуждать, более того, агенты - это существа активные, то есть, они ставят перед собой цели, планируют свои действия и целесообразно действуют.

При этом, взаимодействие между эмоциональностью и рациональностью в модели ОСС, трактуется как процесс с обратными связями, когда сфера эмоций представлена не просто как многоуровневый реактивный механизм на стимулы, но как активно взаимодействующая $\mathrm{c}$ рациональностью. Это приводит к тому, что эмоциональность влияет на принятие решений, а также планирование и осуществление действий так же, как и рациональность может влиять на эмоции, их переживание и интенсивность переживания, а также степень обратного влияния.

Таким образом, на первый взгляд, в теории эмоции ОСС, делается попытка преодолеть односторонности перечисленных выше вариантов иррационализма по отношению к сфере эмоций. И это вполне естественно, если учитывать, что теория ОСС развивалась в значительной степени в русле того направления современной психологии, которое называют когнитивной психологией, и одно из важнейших допущений, лежащих в основаниях ОСС, является допущение изначальной когнитивной осознаваемости эмоциональной сферы и способности, не только теоретика, стоящего в позиции рационализирующего наблюдателя и исследователя, но и изучаемых агентов, к ее рационализации.

\section{Парадигма BDI, этика и теория эмоций.}

А как быть с моральностью человека? Здесь уместно отметить, еще об одной парадигме, лежащей в основаниях теории ОСС и ее более поздних интерпретаций. Это так называемая парадигма BDI (Belief, Desire, Intention - Убеждение, Желание, Намерение). Данная парадигма позволяет объяснять поведение агентов через выбор осуществляемых ими действий с использованием трех ключевых понятий: убеждения, желания и намерения.

Концепт убеждения является достаточно универсальным эпистемическим концептом, объединяющим в рамках парадигмы BDI концепты знания, веры, перцептивно полученной информации, вообще любой информации, которую агент когнитивно осознал и может сформулировать в языке. Сюда же можно отнести и моральные правила, нормы и запреты, которых придерживается (по тем или иным причинам агент). Агент может менять свои убеждения в зависимости от тех или иных обстоятельств и ситуаций, убеждения могут носить различную степень общности (универсальности), в зависимости количества агентов, имеющих одинаковые убеждения; количество агентов, обладающих одинаковыми убеждениями, может меняться в зависимости от различных факторов, в том числе и коммуникативных.

Концепт желания в рамках данной парадигмы определяется в терминах целей, то есть тех состояний мира, ситуаций, и состояний собственного убеждения, которые агент стремиться достигнуть с помощью своих действий (или бездействия).

Концепт намерения в рамках парадигмы BDI определяется в терминах действий и планов (состоящих из действий), которых агент придерживается при выполнении действий, направленных на достижение целей. 
Парадигма BDI позволяет уточнить подход к пониманию моральных дилемм различными способами, из которых нам ближе позиция, отрицающая абсолютно универсальный характер моральных кодексов (так сказать, пригодных для всех обстоятельств и всех агентов). Как пишет В.А.Канке, «Не существует добро вообще, справедливость вообще, свобода вообще и т.д. Широко распространенные суждения об общечеловеческих философских ценностях - плод досужих вымыслов, плохой ориентации в мире науки. .... юбая теория вне фактов, любая этика вне поступков это всего лишь вымысел.» [4, С. 236]. А это означает, что и разделение этической теории на деонтическую и аксиологическую составляющие предполагает, что нет универсальных обязательств, о чем свидетельствует сам факт возникновения моральных дилемм, как связанных с конкретными ситуациями выбора в конкретных обстоятельствах. Здесь прав Э.Ф.Караваев, заявляя, что деонтические формулировки надо рассматривать скорее как принципы или рекомендации, чем как детерминистические генераторы алгоритмов действий [11]. Точно также нет универсальных оценочных шкал, более того, относительно аксиологической составляющей этики также приходится констатировать эмпирическую подтверждаемость «эффекта Кондорсе», связанного с логическими следствиями нетранзитивности отношения предпочтения, основанного на оценочной шкале.

Это означает, что структура отношений между множествами убеждений, желаний и намерений может структурироваться различными способами, и среди них нет единственно приемлемого.

\section{Вместо заключения}

1. Современный эмотивизм в значительной степени опирается на результаты и фактографический материал современных психологии и нейронаук. При этом, мы по-прежнему можем выделить широкий спектр современных позиций на шкале эмотивизм/антиэмотивизм.

2. Преодоление крайних позиций на шкале эмотивизм/морализм требует поиска синтеза теоретических позиций и построения взаимодополняющих теорий. И здесь парадигма BDI может выполнить функцию более универсального подхода. Не случайно эта парадигма широко применяется не только в когнитивных науках, но и в практических разработках архитектур систем искусственного интеллекта.

3. Соединение теории эмоций ОСС с интерпретированной на основе парадигмы BDI не только морально-этической составляющей, но и эмотивной, позволяет выйти на синтетический уровень рационализации, где теория эмоций оказывается взаимно дополнительна с этической теорией. Вспомним, что ОСС предполагает трехчастную структуру эмоций, где оценочная часть согласуется с аксиологией, переживание эмоций детерминирует силу их влияния на принятие желаний и решений, а также выбор действий и планов, а эмоциональная регуляция может рассматриваться как обратное (когнитивное) влияние в форме осознанного пересмотра агентом аксиологической составляющей эмоции, а также обратное влияние на степень интенсивности переживания эмоций.

$$
* * *
$$

1. Газзанига М. Кто за главного? Свобода воли с точки зрения нейробиологии; пер. с англ, под ред. А. Якименко. - Москва: Издательство АCT: CORPUS, 2017. - 330 с.

2. Ивин А.А. Современная философия науки. - М.: Высшая школа, 2005. - 592 с.

3. Канеман Д., Тверски А. Рациональный выбор, ценности и фреймы.// Психологический журнал. 2003. - Т. 24. - № 4. - С. 31-42.

4. Канке В.А. Этика ответственности. Теории морали будущего. —. Логос, 2003. — 352 с.

5. Пляскина А.С. Научный доклад по результатам подготовленной научно-квалификационной работы (диссертации) на тему «Взаимодействие мышления и эмоций при решении моральных дилемм». Москва. НИУ ВШЭ. 2019. — https://psychology.hse.ru/mirror/pubs/share/341836587.pdf 
6. Поддьяков А.Н., Пляскина А.С. Инициативная саморефлексия при решении моральных дилемм // Мир психологии. Научно-методический журнал. 2018. №3. с.96-104.

7. Разин А.В. Моральные дилеммы: причины возникновения и способы разрешения. - Дискурсы этики. Альманах. РХГА Санкт-Петербург. 2013. Выпуск 4(5). Стр.104-116

8. Damasio A. Descartes' Error: Emotion, Reason, and the Human Brain. — N.Y.: Putnam Publishing, 1994. $312 p$.

9. Darwin, C. R. The expression of the emotions in man and animals. London: John Murray. 1872. 1st edition. — http://darwin-online.org.uk/content/frameset?itemID=F1142\&viewtype=text\&pageseq=1

10. Cognition and Emotion. Reviews of Current Research and Theories. Edited by Jan De Houwer and Dirk Hermans. New York: Psychology Press. 2010. 347 p.

11. Karavaev. E.F. Logic and Moral Dilemmas. The Proceedings of the Twentieth World Congress of Philosophy. Boston, Massachusetts U.S.A. 10-15 August. $1998 . \quad$ http://www.bu.edu/wcp/Papers/Logi/LogiKara.htm

12. Ortony A., Clore G. L., Collins A. The Cognitive Structure of Emotions. - Cambridge University Press. 1990. $224 \mathrm{p}$.

\section{Синицкий Д.А.}

\section{Теория аффектов Д. Юма, модель эмоций ОСС и парадигма BDI}

Обнинский институт атомной энергетики - филиал ФГБОУ ВО «Национальный исследовательский ядерный университет «МИФИ» (Россия, Обнинск)

doi: $10.18411 / \mathrm{lj}-06-2020-248$

idsp: ljournal-06-2020-248

\section{Аннотация}

Статья посвящена сравнительному анализу теории аффектов Д. Юма, современной психологической теории эмоций А. Ортони, Дж. Л. Клора и А. Коллинза и парадигмы BDI («Убеждение, Желание, Намерение»), восходящей к творчеству Майкла Братмана. С одной стороны, подчеркивается то прямое или опосредованное влияние, которое оказало творчество Д. Юма на современные психологические и эпистемологические теории. С другой стороны, выражается возможность экспликации философской доктрины Д. Юма средствами современных когнитивных наук.

BDI.

Ключевые слова: теория аффектов Д. Юма, модель эмоций ОСС, парадигма

\section{Abstract}

The article is devoted to a comparative analysis of the theory of affects by D. Hume, the modern psychological theory of emotions of A. Ortoni, J. L. Clore and A. Collins and the BDI paradigm ("Belief, Desire, Intention"), dating back to the work of Michael Bratman. On the one hand, the direct or indirect influence that D. Hume's work had on modern psychological and epistemological theories is emphasized. On the other hand, the possibility of explication of the philosophical doctrine of D. Hume by means of modern cognitive sciences is expressed.

Keywords: D. Hume's theory of affects, OCC emotion model, BDI paradigm.

Эмотивизм Д. Юма обычно трактуется как этическая доктрина, опирающаяся на теорию эмоций (отсюда и название, которое стали применять позднее для характеризации этих идей Юма). С точки зрения Д. Юма, моральные правила основываются на некоторых моральных чувствах, например, «чувстве справедливости» и отношении симпатии, истоки которых коренятся в самой психоэмоциональной и коммуникативной природе человека, поэтому человек просто должен следовать этим правилам, уже навязанным ему природой. В целом попытка Д. Юма выстроить таким образом этическую теорию представляла собой переработку и закономерное 